\title{
Anti-Inflammatory and Antioxidative Effects of Alpha Lipoic Acid on Cultured Human Sebocytes
}

\author{
Weon Ju Lee, Dong Hyuk Eun, Seok Min Kim, Jun Young Kim, Yong Hyun Jang, Seok-Jong Lee \\ Department of Dermatology, School of Medicine, Kyungpook National University, Kyungpook National University Hospital, Daegu, Korea
}

\section{Dear Editor:}

Acne vulgaris is a very common cutaneous disorder caused by hormone, sebum production, follicular hyperkeratinization, Propionibacterium acnes and inflammation. Over the last decade, it has become apparent that oxidative stress is linked to the pathogenesis of acne'. Sahib et al. $^{2}$ reported that the oxidative stress of patients with acne was higher than in healthy individuals. Conversely, antioxidant activities have been found to be lower in patients with acne. Therefore, local and systemic antioxidants have been administered to control acne vulgaris ${ }^{3}$. There are numerous antioxidants; including lipoic acid, L-ascorbic acid, $\alpha$-tocopherol, $\beta$-carotene and astaxanthin ${ }^{4}$. Lipoic acid is usually used as an antioxidant agent for the treatment of skin aging; however, reports on the treatment of acne with lipoic acid are limited. Lipoic acid, also known as alpha-lipoic acid; is an organosulfur compound derived from octanoic acid.

Primary human sebocytes were cultured using sebaceous glands obtained from occipital hair follicles. The sebocytes were cultured in Dulbecco's modified Eagle medium (DMEM; Hyclone Laboratories, Logan, UT, USA) in a humidified atmosphere with $5 \% \mathrm{CO}_{2}$ at $37^{\circ} \mathrm{C}$. The culture media were changed from DMEM to Epilife (MEPI500CA; Gibco BRL, Grand Island, NY, USA), and the sebocytes obtained after the second subculture were used. After the determination of alpha-lipoic acid (Sigma, St. Louis, MO, USA) concentration using the Cell Counting Kit-8 (CCK8; Dojindo, Kumamoto, Japan) assay, the human sebocyte culture media were supplemented with $50 \mu \mathrm{M}$ of al- pha-lipoic acid (Fig. 1A). Lipopolysaccharide $(5 \mu \mathrm{g})$ (Sigma) or dihydrotestosterone $\left(10^{-7} \mathrm{M}\right)$ (Sigma) was added into the human sebocyte culture media. An enzyme-linked immunosorbent assay (ELISA) was used for the measurement of biomarker protein expression in cultured human sebocytes after treatment with alpha-lipoic acid $(50 \mu \mathrm{M})$ and lipopolysaccharide $(5 \mu \mathrm{g})$ or dihydrotestosterone $\left(10^{-7} \mathrm{M}\right)$. The ELISA was used for the analysis of biomarkers, including interleukin (IL): IL-1 $\beta$, IL-6, IL-8 and tumor necrosis factor (TNF)- $\alpha$ (R\&D Systems, Shanghai, China); according to the manufacturer's instructions. The TG-S reaction kit (Asan Pharm. Co., Seoul, Korea) was used for the detection of neutral lipids after the treatment of sebocytes with alpha-lipoic acid (50 $\mu \mathrm{M})$, dihydrotestosterone $\left(10^{-7} \mathrm{M}\right)$, or a combination of lipoic acid $(50 \mu \mathrm{M})$ and dihydrotestosterone $\left(10^{-7} \mathrm{M}\right)$. The BioVision lipid peroxidation assay kit (Biovision, Milpitas, CA, USA) was used for the sensitive detection of malondialdehyde assays. The ELISA data were evaluated using analysis of variance statistics (ver. 18.0; IBM Co., Armonk, NY, USA). The data were considered statistically significant when $p<0.05$.

The treatment of cultured human sebocytes with alpha-lipoic acid $(50 \mu \mathrm{M})$ showed a statistically significant decrease in protein expression of IL- $1 \beta$, IL- 6 and IL-8 compared to control $(p<0.05)$ (Fig. 1B). The treatment of cultured human sebocytes with alpha-lipoic acid $(50 \mu \mathrm{M})$ and dihydrotestosterone $\left(10^{-7} \mathrm{M}\right)$ also showed a statistically significant decrease in protein expression of IL- $1 \beta$, IL-6 and IL-8 compared to control $(p<0.05)$ (Fig. 1B). In

Received January 10, 2018, Revised February 9, 2018, Accepted for publication February 21, 2018

Corresponding author: Weon Ju Lee, Department of Dermatology, Kyungpook National University Hospital, 130 Dongdeok-ro, Jung-gu, Daegu 41944, Korea. Tel: 82-53-420-5838, Fax: 82-53-426-0770, E-mail: weonju@knu.ac.kr ORCID: https://orcid.org/0000-0001-5708-1305

This is an Open Access article distributed under the terms of the Creative Commons Attribution Non-Commercial License (http://creativecommons.org/ licenses/by-nc/4.0) which permits unrestricted non-commercial use, distribution, and reproduction in any medium, provided the original work is properly cited.

Copyright (C) The Korean Dermatological Association and The Korean Society for Investigative Dermatology 
A
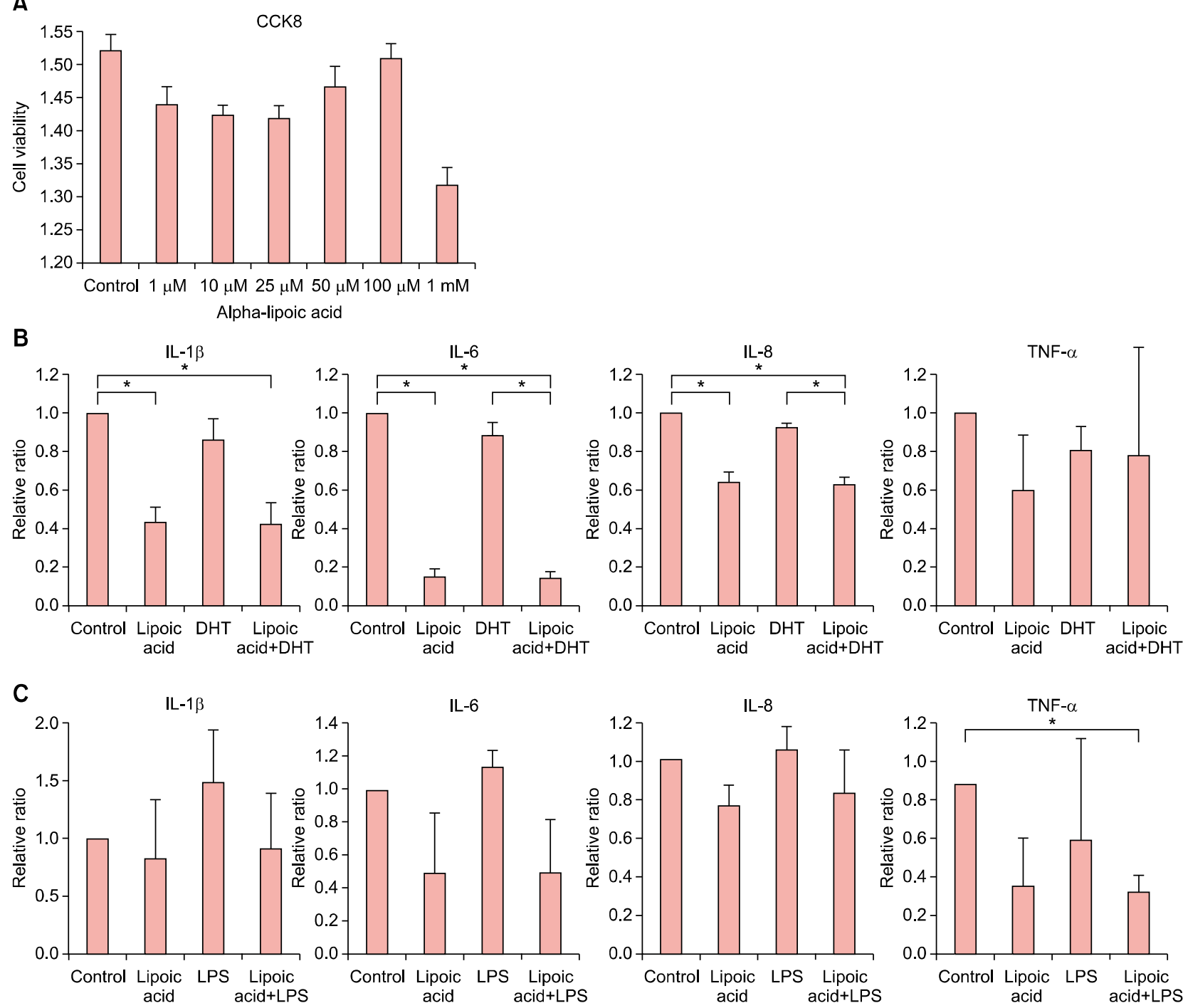

Fig. 1. (A) Cell Counting Kit-8 (CCK8) assay at different concentrations of alpha-lipoic acid. (B) Protein expression of inflammatory biomarkers in cultured human sebocytes after treatment with $50 \mu \mathrm{M}$ of alpha-lipoic acid (lipoic acid) and/or $10^{-7} \mathrm{M}$ of dihydrotestosterone (DHT) on the enzyme-linked immunosorbent assay (ELISA). (C) Protein expression of inflammatory biomarkers in cultured human sebocytes after treatment with $50 \mu \mathrm{M}$ of alpha-lipoic acid (lipoic acid) and/or $5 \mu \mathrm{g}$ of lipopolysaccharide (LPS) on the ELISA. IL: interleukin, TNF: tumor necrosis factor. ${ }^{*} p<0.05$.

addition, the treatment of cultured human sebocytes with alpha- lipoic acid $(50 \mu \mathrm{M})$ and dihydrotestosterone $\left(10^{-7} \mathrm{M}\right)$ showed a statistically significant decrease in protein expression of IL-6 and IL-8 compared to the treatment with dihydrotestosterone $\left(10^{-7} \mathrm{M}\right)(p<0.05)$ (Fig. 1B). The treatment of cultured human sebocytes with lipopolysaccharide (5 $\mu \mathrm{g}$ ) insignificantly increased protein expression of IL-1 $\beta$, IL-6 and IL-8 compared to control (Fig. 1C). The treatment of cultured human sebocytes with alpha-lipoic acid (50 $\mu \mathrm{M})$ and lipopolysaccharide $(5 \mu \mathrm{g})$ insignificantly decreased protein expression of IL- $1 \beta$, IL- 6 and IL-8 compared to control (Fig. 1C). In addition, the treatment of cultured human sebocytes with alpha-lipoic acid (50 $\mu \mathrm{M})$ and lip- opolysaccharide $(5 \mu \mathrm{g})$ insignificantly decreased protein expression of IL- $1 \beta$, IL-6, IL- 8 and TNF- $\alpha$ compared to the treatment with lipopolysaccharide (5 $\mu \mathrm{g}$ ) (Fig. 1C). There was no significant influence of alpha-lipoic acid $(50 \mu \mathrm{M})$ and/or dihydrotestosterone $\left(10^{-7} \mathrm{M}\right)$ on the sebum production of cultured human sebocytes (Fig. 2A). Alpha-lipoic acid (50 $\mu \mathrm{M}$ ) insignificantly decreased lipid peroxidation in cultured human sebocytes (Fig. 2B). Dihydrotestosterone $\left(10^{-7} \mathrm{M}\right)$ insignificantly increased lipid peroxidation in cultured human sebocytes (Fig. 2B). Lipid peroxidation in cultured human sebocytes after treatment with both alpha-lipoic acid $(50 \mu \mathrm{M})$ and dihydrotestosterone $\left(10^{-7} \mathrm{M}\right)$ was insignificantly decreased compared to control or the 

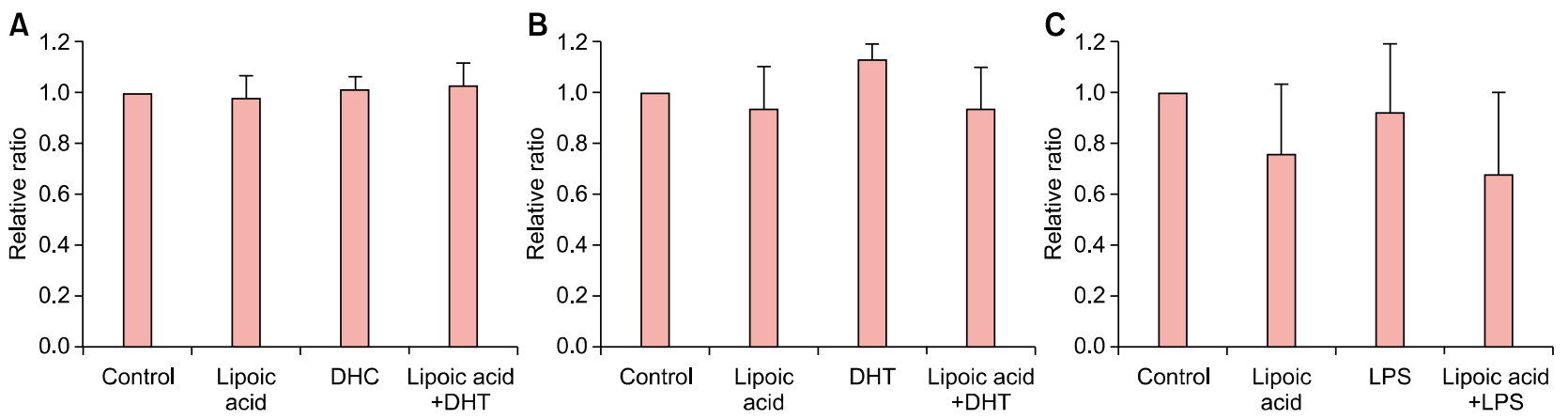

Fig. 2. (A) Sebum production in cultured human sebocytes after treatment with $50 \mu \mathrm{M}$ of alpha-lipoic acid (lipoic acid) and/or $10^{-7}$ $\mathrm{M}$ of dihydrotestosterone (DHT). (B) Lipid peroxidation in cultured human sebocytes after treatment with $50 \mu \mathrm{M}$ of alpha-lipoic acid (lipoic acid) and/or $10^{-7} \mathrm{M}$ of DHT. (C) Lipid peroxidation in cultured human sebocytes after treatment with $50 \mu \mathrm{M}$ of alpha-lipoic acid (lipoic acid) and/or $5 \mu \mathrm{g}$ of lipopolysaccharide (LPS).

treatment with dihydrotestosterone $\left(10^{-7} \mathrm{M}\right)$ (Fig. 2B). Lipid peroxidation in cultured human sebocytes after treatment with alpha-lipoic acid $(50 \mu \mathrm{M})$ and lipopolysaccharide (5 $\mu \mathrm{g}$ ) was insignificantly decreased (Fig. 2C).

Oxidative stress has been related to the pathogenesis of various skin diseases, including acne vulgaris. Potent reactive oxygen species can be generated in acne through damage to the follicular epithelium by inflammatory cells ${ }^{5}$. Oxidative stress in skin can also be induced by ultraviolet B irradiation ${ }^{6}$. In addition, lipopolysaccharide and Propionibacterium acnes can cause oxidative stress in the $\mathrm{skin}^{7}$. Antioxidants including lipoic acid can be used to treat patients with acne, however, it is unclear whether or not androgens are antioxidants. It was reported that testosterone can act as an anti-oxidizing agent in collagen-induced arthritis in rats ${ }^{8}$. On the contrary, it has also been reported that physiological levels of androgens can increase oxidative stress in androgen-responsive prostate carcinoma cells ${ }^{9}$. In this study, lipid peroxidation was decreased after treatment of cultured human sebocytes with alpha-lipoic acid. In addition, dihydrotestosterone slightly increased lipid peroxidation. Furthermore, alpha-lipoic acid decreased lipid peroxidation after treatment of cultured human sebocytes with dihydrotestosterone. In addition, treatment with both alpha-lipoic acid and lipopolysaccharide showed a decreased tendency towards lipid peroxidation compared to treatment with lipopolysaccharide alone. Inflammatory biomarkers, including IL-1 $\beta$, IL-6, IL-8 and TNF- $\alpha$, have been linked to the pathogenesis of inflammatory acne. Lipoic acid inhibited the expression of these inflammatory biomarkers. Despite the addition of dihydrotestoterone or lipopolysaccharide to the cultured human sebocytes, lipoic acid still inhibited the expression of the inflammatory biomarkers. Both dihydrotestosterone and lipopolysaccharide can upregulate the expression of inflammatory biomarkers in cultured human sebocytes ${ }^{10}$. The mechanism by which lipoic acid inhibits the expression of inflammatory biomarkers should be elucidated. Dihydrotestosterone is well known to influence sebum production and secretion. Human sebaceous glands, which are the sources of sebum production; express a variety of factors related to androgen biosynthesis. However, since primary cultured human sebocytes differ to sebocytes in vivo, cultured human sebocytes may show limited sebocyte differentiation even when incubated with androgens. Transcription factors such as CCAAT/enhancer binding proteins and peroxisome proliferator-activated receptors, in addition to androgens are very important for sebocyte production of sebum. In this study, dihydrotestosterone did not result in a significant increase in sebum production. Lipoic acid also did not influence sebum production in cultured human sebocytes. Therefore, we propose that lipoic acid is an antioxidant, and it acts as an anti-inflammatory agent.

\section{CONFLICT OF INTEREST}

The authors have nothing to disclose.

\section{ORCID}

Weon Ju Lee, https://orcid.org/0000-0001-5708-1305 Dong Hyuk Eun, https://orcid.org/0000-0003-4044-0679 Seok Min Kim, https://orcid.org/0000-0001-6470-7986 Jun Young Kim, https://orcid.org/0000-0002-2999-1018 Yong Hyun Jang, https://orcid.org/0000-0003-1706-007X Seok-Jong Lee, https://orcid.org/0000-0002-6131-632X 


\section{REFERENCES}

1. Bowe WP, Patel N, Logan AC. Acne vulgaris: the role of oxidative stress and the potential therapeutic value of local and systemic antioxidants. J Drugs Dermatol 2012;11:742-746.

2. Sahib AS, Al-Anbari HH, Raghif ARA. Oxidative stress in acne vulgaris: an important therapeutic target. J Mol Pathophysiol 2013;2:27-31.

3. Kovalev VM. [Complex treatment of acne with lipoic acid]. Vrach Delo 1981;(3):108-113. Russian.

4. Li X, Yang Z, Bai Y. Fluorescence spectroscopic analysis of the interaction of papain and bromelain with I-ascorbic acid, a-tocopherol, $\beta$-carotene and astaxanthin. Int J Biol Macromol 2018;107:144-156.

5. Choi CW, Choi JW, Park KC, Youn SW. Facial sebum affects the development of acne, especially the distribution of inflammatory acne. J Eur Acad Dermatol Venereol 2013; 27:301-306.

6. Chang TM, Tsen JH, Yen H, Yang TY, Huang HC. Extract from periostracum cicadae inhibits oxidative stress and inflammation induced by ultraviolet $\mathrm{B}$ irradiation on $\mathrm{HaCaT}$ keratinocytes. Evid Based Complement Alternat Med 2017; 2017:8325049.

7. Bromfield JJ, lacovides SM. Evaluating lipopolysaccharideinduced oxidative stress in bovine granulosa cells. J Assist Reprod Genet 2017;34:1619-1626.

8. Ganesan K, Tiwari M, Balachandran C, Manohar BM, Puvanakrishnan R. Estrogen and testosterone attenuate extracellular matrix loss in collagen-induced arthritis in rats. Calcif Tissue Int 2008;83:354-364.

9. Ripple MO, Henry WF, Rago RP, Wilding G. Prooxidantantioxidant shift induced by androgen treatment of human prostate carcinoma cells. J Natl Cancer Inst 1997;89:40-48.

10. Lee WJ, Kim SL, Choe YS, Jang YH, Lee SJ, Kim DW. Magnesium ascorbyl phosphate regulates the expression of inflammatory biomarkers in cultured sebocytes. Ann Dermatol 2015;27:376-382.

\title{
Plasmacytoid Dendritic Cells in Pityriasis Rubra Pilaris
}

\author{
Jana Al-Hage*, Randa Akel*, Mazen Kurban, Ossama Abbas \\ Department of Dermatology, American University of Beirut Medical Center, Beirut, Lebanon
}

\section{Dear Editor:}

Plasmacytoid dendritic cells (pDCs) are bone marrow-derived DCs with plasma cell morphology. They are lineage negative and express CD4, CD123, HLA-DR, blood-derived dendritic cell antigen-2 (BDCA-2) and Toll-like receptor (TLR) 7 and TLR9 within endosomal compartments ${ }^{1}$. When activated, TLRs initiate a cascade of multiple signaling pathways that ultimately lead to production of pro-inflammatory cytokines such as type I interferons (INFs) and, to a lesser extent, IL- 6 and TNF- $\alpha$. This cytokine profile, especially type I IFN, is responsible for pDCs' anti-viral effect as well as their ability to link innate and adaptive immunity ${ }^{1}$. In addition to their role in cancer immunity and cutaneous viral infections, pDCs have pathogenetically been implicated in several inflammatory skin diseases such as lupus erythematosus (LE), psoriasis, lichen planus, alopecia areata, among others ${ }^{1}$.

Pytiriasis rubra pilaris (PRP) is a rare idiopathic papulosqu-

Received October 25, 2017, Revised January 24, 2018, Accepted for publication February 23, 2018

Corresponding author: Ossama Abbas, Department of Dermatology, American University of Beirut Medical Center, Riad El Solh St., P.O.Box 11-0236, Beirut 11072020, Lebanon. Tel: 961-1-350000, ext. 7915, Fax: 961-1-745320, E-mail: ossamaabbas2003@yahoo.com ORCID: https://orcid.org/0000-0001-6970-8056

*These authors have equally contributed to the article.

This is an Open Access article distributed under the terms of the Creative Commons Attribution Non-Commercial License (http://creativecommons.org/ licenses/by-nc/4.0) which permits unrestricted non-commercial use, distribution, and reproduction in any medium, provided the original work is properly cited.

Copyright (C) The Korean Dermatological Association and The Korean Society for Investigative Dermatology 